\title{
SCIENTIFIC REPORTS

\section{Analysis of the inhibiting activity of reversion-inducing cysteine-rich protein with Kazal motifs (RECK) on matrix metalloproteinases}

\author{
Soraia R. Mendes ${ }^{1}$, Laura del Amo-Maestro ${ }^{1}$, Laura Marino-Puertas ${ }^{1}$, Iñaki de Diego ${ }^{1,2}$, \\ Theodoros Goulas ${ }^{1} \&$ F. Xavier Gomis-Rüth ${ }^{1 *}$
}

Matrix metalloproteinases (MMPs) occur in 23 human paralogues with key functions in physiology, and their activity is controlled by protein inhibitors. Reversion-inducing cysteine-rich protein with Kazal motifs (RECK), which is essential for embryogenesis and tumour suppression, has been reported to inhibit MMPs. Here, we developed eukaryotic and bacterial expression systems for different RECK variants and analysed their inhibitory capacity against representative MMPs in vitro. We could not detect any significant inhibition. Instead, we found that partially purified RECK from the conditioned medium of transfected Expi293F cells but not that of ExpiCHO-S or Drosophila Schneider cells contained a contaminant with proteolytic activity. The contaminant was removed through treatment with a small-molecule serine peptidase inhibitor and additional chromatographic purification. A tantamount contaminant was further detected in an equivalent expression system of the $\mathrm{N}$-terminal fragment of the proteoglycan testican 3, but not in those of two other proteins. These results indicate that previous reports of inhibitory activity of recombinant RECK on MMPs, which were performed with partially purified samples, were probably masked by a coeluting contaminant present in the supernatant of HEK293-derived cells. Thus, RECK is probably not a direct inhibitor of MMP catalytic activity but may still regulate MMPs through other mechanisms.

Proteolysis is a post-translational modification of proteins and peptides that is essential for all physiological pathways. It is exerted by peptidases, among which metallopeptidases (MPs) are one of several chemical classes and consist of various clans and families ${ }^{1}$. The matrix metalloproteinases (MMPs; 23 paralogues in humans), as well as the ADAMs/adamalysins (19 in humans) and the more distantly related ADAMTSs (19 in humans) are among the most studied MPs because of their enormous relevance for human health and disease $\mathrm{e}^{2-8}$. Collectively, they carry out functions as broad degraders during the digestion of intake proteins, turnover of extracellular-matrix components for tissue remodelling and developmental processes, and clearance of obsolete or malfunctioning polypeptides. Moreover, they are fine regulators of shedding, maturation and inactivation of other proteins through limited proteolysis of one or a few peptide bonds ${ }^{9}$. Peptide-bond scission is normally irreparable under physiological conditions, so MPs must be fastidiously controlled to avoid aberrant cleavage that would cause dysfunction and pathology. This regulation is physiologically carried out for MMPs in humans by four tissue inhibitors of metalloproteinases and the broad-spectrum pan-peptidase inhibitor $\alpha_{2}$-macroglobulin ${ }^{3,10-12}$. Another reported inhibitor is the protein $\mathrm{RECK}^{13-17}$.

RECK, an acronym for reversion-inducing cysteine-rich protein with Kazal motifs, is encoded by a gene that suppresses the transformed phenotype caused by ras oncogenes ${ }^{13,18}$. The 971 -residue molecule is a membrane-anchored glycoprotein of $\sim 125 \mathrm{kDa}$, which contains an N-terminal signal peptide for secretion, a region spanning five cystine knots (KNs; KN1-KN5), a region with three repeats similar to Kazal inhibitors of serine endopeptidases (KLs; KL1-KL3) ${ }^{19,20}$, and a C-terminal segment (CTS; residues $\mathrm{A}^{943}$ - $\mathrm{N}^{971}$; for numbering, see UniProt database entry [UP] O95980) (Fig. 1). The CTS is removed during maturation, which leads to binding

${ }^{1}$ Proteolysis Laboratory, Department of Structural Biology, Molecular Biology Institute of Barcelona, Higher Scientific Research Council (CSIC), Barcelona Science Park, Helix Building, Baldiri Reixac, 15-21, 08028, Barcelona, Catalonia, Spain. ${ }^{2}$ Present address: ALBA Synchrotron Light Source, Carrer de la Llum, 2-26, 08290, Cerdanyola del Vallés, Catalonia, Spain. *email:xgrcri@ibmb.csic.es 


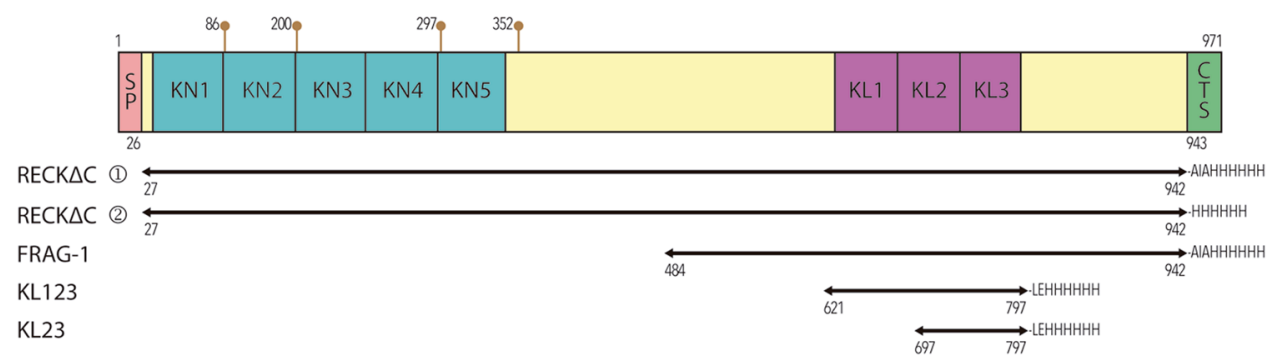

Figure 1. Overview of RECK constructs. Scheme depicting the domain structure of human RECK. SP, signal peptide; KN1-KN5, cysteine knot regions; KL1-KL3, Kazal-like domains; and CTS, C-terminal segment. The distinct constructs that were studied in this work are shown and labelled. 1), RECK $\Delta$ C produced in Expi or Expi-CHO cells. (2), RECK $\Delta$ C produced in S2 cells. Brown lollipops pinpoint glycosylation sites according to ${ }^{22}$.

of RECK to the plasma membrane through a glycosylphosphatidylinositol anchor attached to $\mathrm{S}^{942} 13,21$. In addition, $N$-linked glycosylations have been determined at residues $\mathrm{N}^{200}, \mathrm{~N}^{86}, \mathrm{~N}^{297}$ and $\mathrm{N}^{352}$, and the latter three are essential for function ${ }^{22}$.

Physiologically, RECK is critical because knockout mice die during embryonic development with severe tissue, vascular, and neuronal defects ${ }^{14,23}$. It is highly expressed in most normal tissues and non-transformed cells, and is probably involved in myogenesis, chondrogenesis, patterning during embryogenesis, and the establishment of the neuromuscular junction ${ }^{13,17,24}$. It also participates in Notch-dependent neurogenesis, Wnt signalling and brain angiogenesis ${ }^{25-27}$. Moreover, it has been implicated in tumour processes including growth, angiogenesis, invasion, metastasis and relapse ${ }^{14,28,29}$. It is downregulated with poor prognosis for disease outcome in pancreatic, oral, breast, prostate and non-small cell lung cancers, as well as in osteosarcoma ${ }^{30-35}$. Consistently, restored expression of RECK in tumour cells suppresses angiogenesis, invasion and metastasis in animal models, and the level of residual RECK expression in tumour tissues correlates with better prognosis ${ }^{17}$. All these findings suggest that RECK has a potential therapeutic value as a tumour suppressor for the treatment of malignant conditions ${ }^{21}$.

At the molecular level, RECK binds ADAMTS-10, which is involved in connective-tissue development ${ }^{36}$, and impairs modulation of Notch signalling during neurogenesis mediated by ADAM- $10^{23}$. RECK without the CTS $(\mathrm{RECK} \Delta \mathrm{C})$ has further been described to prevent cleavage by ADAM-10 of a fragment of protein Delta1 and of a synthetic substrate with an apparent inhibition constant $\left(K_{\mathrm{i}}\right)$ of $<15 \mathrm{nM}^{23}$. Moreover, RECK $\Delta \mathrm{C}$ has been claimed to directly inhibit cleavage of fluorogenic peptide substrates by MMP-2, MMP-9 and MMP-14 with associated $K_{\mathrm{i}}$ values of 20-80 $\mathrm{nM}^{13-15,17}$, and of plasma fibronectin by both MMP-2 and MMP-7, the latter with a $K_{\mathrm{i}}$ of $\sim 41 \mathrm{nM}^{17}$. In a report by another group ${ }^{16}$, tagged RECK $\Delta \mathrm{C}$ and shorter constructs spanning the two C-terminal Kazal-like motifs $\left(\mathrm{P}^{676}-\mathrm{V}^{799}\right)$, the cysteine knots (residues $\mathrm{L}^{285}-\mathrm{R}^{368}$ ) and all three Kazal-like motifs (residues $\mathrm{A}^{605}-\mathrm{V}^{799}$ ), respectively, were assayed for inhibition of MMP-9 with fluorescein-conjugated gelatine as substrate. The authors have reported that the two former constructs but not the two latter significantly inhibit gelatine cleavage ${ }^{16}$. Based on all these reports, RECK has been included as an MMP inhibitor in the MEROPS database under family I1, which groups the Kazal family of inhibitors of serine endopeptidase families S1 and S8 $8^{19,20,37}$.

Prompted by these results, we embarked on a long-term project to characterize the structure and function of RECK. To this aim, we here produced several constructs of the protein with the highest purity as a requisite for molecular and biophysical studies, and we assayed their inhibitory capacity against MMPs in vitro.

\section{Materials and Methods}

Expression vectors. Plasmid pBS-hRECK (for details on constructs, plasmids, vectors and primers, see Table 1) encoding full-length human RECK cDNA in the pBlueScript vector was kindly provided by Makoto Noda, Kyoto (Japan). Constructs encoding fragments RECK $\Delta \mathrm{C}$ (plasmid pS6-RECK $\Delta$ C; residues $\mathrm{G}^{27}-\mathrm{S}^{942}$ ), KL123 (pCri9a-KL123; $S^{621}-S^{797}$ ) and KL23 (pCri9a-KL23; $T^{697}-S^{797}$ ) (Fig. 1), as well as the coding sequence for residues $\mathrm{A}^{22}-\mathrm{Q}^{313}$ (UP Q9BQ16) of the $\mathrm{N}$-terminal region of human testican 3 (N-TES; plasmid pS6-NTES) in a synthetic gene (from GenScript) were amplified with primers that introduced sites for directional cloning. For bacterial expression, plasmid pCri9 $\mathrm{a}^{38}$, which adds a C-terminal hexahistidine $\left(\mathrm{His}_{6}\right)$-tag, was used for insertion between the $\mathrm{NcoI}$ and $\mathrm{XhoI}$ restriction sites. For expression in mammalian cells, vector pCMV-Sport 6 (Thermo Scientific) with the original signal peptide (for RECK $\Delta \mathrm{C}$ ) or with the mouse immunoglobulin $\kappa$ leader sequence (for N-TES) was used to insert genes between SmaI/AsiSI and BstEII/AsiSI restriction sites, respectively. For expression of RECK $\triangle \mathrm{C}$ in insect cells, the RECK gene was inserted into vector pIEx (Novagen) by restriction-free cloning in frame with the signal peptide of adipokinetic hormone as previously described ${ }^{39}$ to yield plasmid pIERECK $\triangle$ C. Primers and DNA-modifying enzymes for polymerase chain reaction (PCR) steps were purchased from Sigma-Aldrich and Thermo Scientific, respectively. PCR was performed with Phusion High Fidelity DNA polymerase (Thermo Scientific) according to the manufacturer's instructions with an extra optimization step by thermal gradient after each reaction. DNA was purified with the OMEGA Biotek Purification Kit (Omega) or GeneJET Plasmid MaxiPrep Kit (Thermo Scientific) according to the manufacturer's instructions, and all constructs were verified by DNA sequencing. Plasmid pET3a-MT1 $\Delta \mathrm{C}$ (see Table 1) encoding the pro- and catalytic domains of MMP-14 (S $\mathrm{S}^{24}-\mathrm{G}^{284}$; UP P50281) plus an extra N-terminal methionine ${ }^{40}$ was kindly provided by Yoshifumi Itoh, Oxford (UK). 


\begin{tabular}{|c|c|c|c|c|c|c|}
\hline Plasmid name & Protein & Parental vector(s) & Forward-primer* & Reverse-primer* & Protein sequence $* *$ & Tag*** \\
\hline pS6-RECK $\Delta C$ & $\operatorname{RECK} \Delta \mathrm{C}$ & $\begin{array}{l}\text { pBS-hRECK } \\
\text { pCMV-Sport6 }\end{array}$ & $\begin{array}{l}\text { ATGCCCCGGGATGGCGA } \\
\text { CCGTCCGG }\end{array}$ & $\begin{array}{l}\text { GCATGCGATCGCCGATG } \\
\text { GCACACTGCTG }\end{array}$ & $\mathrm{G}^{27}-\mathrm{S}^{942}+\mathbf{A I A}+\mathbf{H}_{\mathbf{6}}$ & $\mathrm{His}_{6}$ \\
\hline pIE-RECK $\Delta C$ & $\operatorname{RECK} \Delta \mathrm{C}$ & $\begin{array}{l}\text { pBS-hRECK } \\
\text { pIEx }\end{array}$ & $\begin{array}{l}\frac{\text { TCATCGCTTTCGTCATCA }}{\text { TCGCTGGGCCTGGCTCC }} \\
\text { GGGCAGTGCGGGTG }\end{array}$ & $\begin{array}{l}\text { AAACTCAATGGTGATG } \\
\text { GTGATGATGCGATGGCA } \\
\text { CACTGCTGGAGACCTGT }\end{array}$ & $\mathrm{G}^{27}-\mathrm{S}^{942}+\mathbf{H}_{\mathbf{6}}$ & $\mathrm{His}_{6}$ \\
\hline pS6-NTES & N-TES & $\begin{array}{l}\text { Synthetic DNA } \\
\text { pCMV-Sport6 }\end{array}$ & $\begin{array}{l}\text { ATGCGGTGACCTAGC } \\
\text { TGCCGCGGCGGT }\end{array}$ & $\begin{array}{l}\text { GCATGCGATCGCTTGCTG } \\
\text { TCTCTGGAAGCA }\end{array}$ & $\mathbf{L}+\mathrm{A}^{22}-\mathrm{Q}^{313}+\mathbf{A I A}+\mathbf{H}_{\mathbf{6}}$ & $\mathrm{His}_{6}$ \\
\hline pCri9a-KL23 & KL23 & $\begin{array}{l}\text { pS6-RECK } \Delta C \\
\text { pCri9a }\end{array}$ & $\begin{array}{l}\text { ATGCCCATGGTAACGAC } \\
\text { TTTTGATAA }\end{array}$ & $\begin{array}{l}\text { GCATCTCGAGGCTGTGCT } \\
\text { CTGAGAGG }\end{array}$ & $\mathbf{V}+\mathrm{T}^{697}-\mathrm{S}^{797}+\mathbf{L E}+\mathbf{H}_{\mathbf{6}}$ & $\mathrm{His}_{6}$ \\
\hline pCri9a-KL123 & KL123 & $\begin{array}{l}\text { pS6-RECK } \Delta C \\
\text { pCri9a }\end{array}$ & $\begin{array}{l}\text { ATGCCCATGGTATCAGA } \\
\text { AGATGACCG }\end{array}$ & $\begin{array}{l}\text { GCATCTCGAGGCTGTGCT } \\
\text { CTGAGAGG }\end{array}$ & $\mathbf{V}+S^{621}-S^{797}+\mathbf{L E}+\mathbf{H}_{\mathbf{6}}$ & $\mathrm{His}_{6}$ \\
\hline pET3a-MT1 $\Delta C$ & MMP-14 CD & pET3a & - & - & $\mathbf{M}+\mathrm{S}^{24}-\mathrm{G}^{284}$ & None \\
\hline
\end{tabular}

Table 1. Constructs, primers, plasmids and proteins. All constructs are for extracellular expression of the respective proteins. *Restriction-site sequences and overhangs for restriction-free cloning are underlined. **Peptide sequence of the expressed protein. Amino acids derived from the construct are in bold. See also Fig. 1. ***Tag fused to the carboxy-terminus.

Eukaryotic cell culture and transient transfection. Drosophila melanogaster embryonic Schneider cells (S2; Gibco) adapted to suspension, as well as the HEK293-derived Expi293F cells (Expi; Gibco) and ExpiCHO-S derived from Chinese hamster ovary cells (Expi-CHO; Gibco), were maintained in Sf-900 II SFM and FreeStyle F17 expression medium (Gibco) for insect and mammalian cells, respectively. Both media were supplemented with $0.5 \mu \mathrm{g} / \mathrm{mL}$ amphotericin B (Gibco), $100 \mathrm{units} / \mathrm{mL}$ penicillin and $100 \mu \mathrm{g} / \mathrm{mL}$ streptomycin (Sigma). Additionally, FreeStyle F17 medium was supplemented with $8 \mathrm{mM} \mathrm{L}$-glutamine and 0.2\% Pluronic F-68 (Gibco).

Expi and Expi-CHO cells were grown to a density of $3-5 \times 10^{6}$ cells $/ \mathrm{mL}$ and $4-6 \times 10^{6}$ cells $/ \mathrm{mL}$, respectively, and subcultured every 3-4 days by dilution to $0.3-0.5 \times 10^{6}$ cells $/ \mathrm{mL}$ and $0.2-0.3 \times 10^{6}$ cells $/ \mathrm{mL}$, respectively. To this aim, they were incubated at $37^{\circ} \mathrm{C}$ in a Multitron Cell Shaker Incubator (Infors HT) at $150 \mathrm{rpm}$ in humidified atmosphere with $8 \% \mathrm{CO}_{2}$. Cells were then subcultured to $0.7 \times 10^{6}$ cells $/ \mathrm{mL}$ and transfected after $24 \mathrm{~h}$ at a cell density of $1 \times 10^{6}$ cells $/ \mathrm{mL}$ with a dropwise added mixture of $1 \mathrm{mg}$ of vector DNA (see Table 1 ) and $3 \mathrm{mg}$ of linear $25-\mathrm{kDa}$ polyethyleneimine (Polysciences Europe) in $20 \mathrm{~mL}$ of Opti-MEM medium (Gibco) per litre of expression medium. The mixture had been previously incubated at room temperature for $15-20 \mathrm{~min}$. After 3 days, the cell-culture supernatant was harvested for protein purification.

S2 cells were grown to a density of $12-16 \times 10^{6}$ cells $/ \mathrm{mL}$, subcultured by dilution to $4 \times 10^{6}$ cells $/ \mathrm{mL}$ every 3-4 days and incubated at $28^{\circ} \mathrm{C}$ in an Innova 42 Incubator Shaker (New Brunswick Scientific) under agitation at $200 \mathrm{rpm}$. Cells were subcultured to $6 \times 10^{6}$ cells $/ \mathrm{mL}$ and transfected after $24 \mathrm{~h}$ at a cell density of $12 \times 10^{6} \mathrm{cells} / \mathrm{mL}$ with a dropwise added mixture of $0.6 \mu \mathrm{g}$ of DNA (see Table 1) and $2 \mu \mathrm{g}$ of linear $25-\mathrm{kDa}$ polyethyleneimine per $10^{6}$ cells. The mixture had been previously incubated at room temperature for $15-30 \mathrm{~min}$. Transfected cells were diluted to $4 \times 10^{6}$ cells $/ \mathrm{mL}$ after $1 \mathrm{~h}$ incubation at $28^{\circ} \mathrm{C}$ under agitation at $200 \mathrm{rpm}$, and the cell-culture supernatant was harvested after 7 days for protein purification.

Bacterial expression. Plasmids pCri9a-KL123 and pCri9a-KL23 were transformed into competent Lemo21 (DE3) Escherichia coli cells (New England Biolabs) and plated on Luria-Bertani (LB) plates. Fifty millilitres of lysogeny broth was inoculated with a single bacterial colony and incubated overnight at $37^{\circ} \mathrm{C}$ under stirring at $220 \mathrm{rpm}$. Five millilitres of this preinoculum was used to inoculate $500 \mathrm{~mL}$ of lysogeny broth, and cells were left to grow at $37^{\circ} \mathrm{C}$ until $\mathrm{OD}_{600} \approx 0.7$. Subsequently, cultures were cooled to $20^{\circ} \mathrm{C}$ and protein expression was induced with $0.4 \mathrm{mM}$ isopropyl- 3 -D-1-thiogalactopyranoside (IPTG; Duchefa) for 18-20 h. LB plates and lysogeny broth were supplemented with $50 \mu \mathrm{g} / \mathrm{mL}$ kanamycin (Fisher Bioreagents) and $34 \mu \mathrm{g} / \mathrm{mL}$ chloramphenicol (Fluka).

For the expression of MMP-14 catalytic domain (CD), E. coli BL21 (DE3) cells (Sigma) were transformed with plasmid pET3a-MT1 $\triangle \mathrm{C}$. One hundred millilitres of lysogeny broth was inoculated with a single colony and incubated overnight at $28^{\circ} \mathrm{C}$ under stirring at $200 \mathrm{rpm}$. Ten millilitres of this preinoculum was used to inoculate $500 \mathrm{~mL}$ of lysogeny broth, and cells were left to grow at $37^{\circ} \mathrm{C}$ until $\mathrm{OD}_{600} \approx 0.6$. Cells were then induced with $0.5 \mathrm{mM}$ IPTG and kept for $5 \mathrm{~h}$ at $37^{\circ} \mathrm{C}$. LB plates and lysogeny broth were supplemented with $100 \mu \mathrm{g} / \mathrm{mL}$ ampicillin (Apollo Scientific).

Protein purification. For purification of RECK $\Delta \mathrm{C}$ from Expi cells, cell-culture supernatant was cleared at $4{ }^{\circ} \mathrm{C}$ by centrifugation at $3,500 \times g$ for $30 \mathrm{~min}$, filter-sterilized and concentrated 20 -fold with a VivaFlow 200 Cross Flow Cassette device with a Hydrosart membrane of $30-\mathrm{kDa}$ cutoff (Sartorius). Concentrated supernatant was then dialysed against a 75-fold volume excess of buffer $20 \mathrm{mM}$ Tris. $\mathrm{HCl}$ pH 7.5, $150 \mathrm{mM}$ sodium chloride. After addition of $20 \mathrm{mM}$ imidazole to the dialysed supernatant, RECK $\Delta \mathrm{C}$ was captured by nickel-nitrilotriacetic acid (Ni-NTA) affinity chromatography (AC) in a HisTrap HP column (GE Healthcare) previously washed with buffer A ( $50 \mathrm{mM}$ Tris. $\mathrm{HCl} \mathrm{pH} \mathrm{7.5,} 1 \mathrm{M}$ sodium chloride, $500 \mathrm{mM}$ imidazole) and equilibrated with buffer A without imidazole. The protein was washed and eluted with a step gradient of imidazole $(2 \%, 4 \%, 12 \%$ and $60 \%$ of buffer A). The presence of a proteolytic impurity in fractions containing RECK $\Delta \mathrm{C}$ was assessed through incubation with $1 \mathrm{mg} / \mathrm{mL}$ fibrinogen from human plasma (Sigma) in buffer B (50 mM Tris. $\mathrm{HCl}$ pH $7.5,150 \mathrm{mM}$ sodium chloride, $5 \mathrm{mM}$ calcium chloride, $50 \mu \mathrm{M}$ zinc chloride) overnight at $37^{\circ} \mathrm{C}$. To remove this contaminant and obtain highly pure RECK $\Delta \mathrm{C}$, the protein was incubated for $1 \mathrm{~h}$ at room temperature with $1 \mathrm{mg} / \mathrm{mL} 4$-[2-aminoethyl] 
benzenesulfonyl fluoride (AEBSF, commercial name Pefabloc, Sigma) and further purified by size exclusion chromatography (SEC) in a Superdex200 (GE Healthcare Life Sciences) column equilibrated with buffer A without imidazole.

For the production and purification of RECK construct FRAG-1 (see Fig. 1), highly purified RECK $\Delta \mathrm{C}$ was incubated with 20 -fold molar excess of MMP-14 CD in buffer B overnight at $37^{\circ} \mathrm{C}$. Cleavage fragments were purified by SEC in a Superdex75 (GE Healthcare Life Sciences) column equilibrated with buffer C ( $50 \mathrm{mM}$ Tris. $\mathrm{HCl}$ $\mathrm{pH} 7.5,150 \mathrm{mM}$ sodium chloride). Presence of proteolytic activity in the fractions containing FRAG-1 was assessed as above with fibrinogen.

For purification of RECK $\Delta \mathrm{C}$ from S2 or Expi-CHO cells, cleared cell culture supernatant was dialysed against

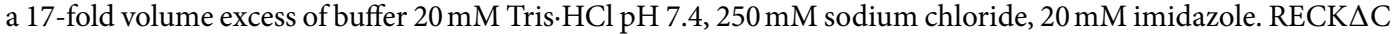
in the supernatant was captured by AC with Ni-NTA resin (Thermo Scientific) by overnight incubation at $4{ }^{\circ} \mathrm{C}$. It was subsequently loaded onto an open column for batch purification (Bio-Rad), and washed extensively and eluted with $4 \%$ and $60 \%$ of buffer A, respectively. The presence of proteolytic activity was assessed as above with fibrinogen. Partially purified protein was further purified by SEC in a Superdex 200 10/300(GE Healthcare) column equilibrated with buffer C (RECK $\Delta \mathrm{C}$ from S2 cells) or buffer A without imidazole (RECK $\Delta \mathrm{C}$ from Expi-CHO cells).

For N-TES purification, cleared cell culture supernatant was supplemented with $20 \mathrm{mM}$ imidazole and incubated for 3-4 h with Ni-NTA resin. It was subsequently loaded onto an open column for batch AC purification (Bio-Rad), and washed extensively and eluted with $4 \%$ and $60 \%$ buffer A, respectively. Eluted fractions were pooled, desalted and concentrated, and the presence of proteolytic activity was assessed as above with fibrinogen. This activity was suppressed as described above and subsequent purification by SEC followed in a Superdex 75 10/300(GE Healthcare) column equilibrated with buffer A without imidazole.

For purification of RECK constructs KL23 and KL123, bacterial cells were harvested by centrifugation at 3,500

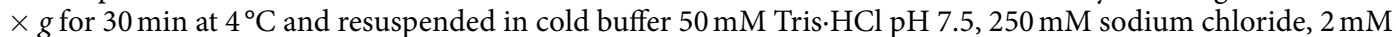
ethylenediaminetetraacetate (EDTA). Cells were lysed with a cell disrupter (Constant Systems) at a pressure of $1.35 \mathrm{kBar}$, and nonclassical inclusion bodies were recovered by centrifugation at $48,000 \times \mathrm{g}$ for $30 \mathrm{~min}$ at $4{ }^{\circ} \mathrm{C}$ and washed first with buffer $100 \mathrm{mM}$ Tris. $\mathrm{HCl} \mathrm{pH} \mathrm{7.5,} \mathrm{cOmplete} \mathrm{EDTA-free} \mathrm{(inhibitor} \mathrm{cocktail;} \mathrm{Roche,} \mathrm{Sigma),}$ $2 \mathrm{M}$ urea, $2 \%$ Triton X-100, and then twice with buffer D (50 mM Tris. $\mathrm{HCl} \mathrm{pH} \mathrm{7.5,} \mathrm{inhibitor} \mathrm{cocktail,} 2 \mathrm{M}$ urea). The washed inclusion bodies were resuspended in buffer $\mathrm{D}$ and kept for $48 \mathrm{~h}$ under stirring at room temperature. Non-solubilised protein was removed by centrifugation at $48,000 \times g$ for $30 \mathrm{~min}$ at $4{ }^{\circ} \mathrm{C}$, and the supernatant was supplemented with $20 \mathrm{mM}$ imidazole. Protein was captured by AC in a HisTrap HP column (GE Healthcare) pre-

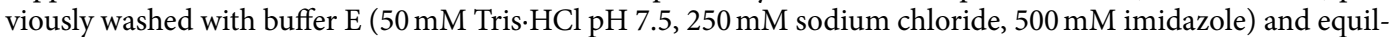
ibrated with buffer $50 \mathrm{mM}$ Tris. $\mathrm{HCl}$ pH 7.5, $250 \mathrm{mM}$ sodium chloride, $20 \mathrm{mM}$ imidazole. The RECK fragments were washed and eluted with $20 \mathrm{mM}$ and $300 \mathrm{mM}$ imidazole $(0 \%$ and $60 \%$ of buffer E), respectively. Partially purified proteins were polished by SEC in a Superdex75 (GE Healthcare) column with buffer C.

Pure MMP-14 CD was obtained from inclusion bodies by adapting a published protocol ${ }^{41}$. Accordingly, bacterial cells were harvested by centrifugation at $3,500 \times g$ for $30 \mathrm{~min}$ at $4^{\circ} \mathrm{C}$ and washed with $20 \mathrm{mM}$ Tris. $\mathrm{HCl} \mathrm{pH}$ $8.0,20 \%$ sucrose for $10 \mathrm{~min}$ at $37^{\circ} \mathrm{C}$ under stirring at $220 \mathrm{rpm}$. Subsequently, cells were resuspended in buffer $\mathrm{F}$ (20 mM Tris. $\mathrm{HCl} \mathrm{pH} \mathrm{8.0)} \mathrm{and} \mathrm{kept} \mathrm{under} \mathrm{gentle} \mathrm{agitation} \mathrm{overnight} \mathrm{at} \mathrm{room} \mathrm{temperature.} \mathrm{Afterwards,} \mathrm{first} \mathrm{deox-}$ ycholate (Sigma) at $1.25 \mathrm{mg} / \mathrm{mL}$ and then DNase I (Roche) at $1 \mathrm{mg} / \mathrm{mL}$ were added to the lysed cells for $3 \mathrm{~h}$. After a further $2 \mathrm{~h}$ incubation, inclusion bodies were harvested by centrifugation at $6,500 \times g$ for $15 \mathrm{~min}$ at $4^{\circ} \mathrm{C}$ and resuspended in buffer F with $0.5 \%$ Triton X-100. Inclusion bodies were then dissolved in buffer $20 \mathrm{mM} \mathrm{Tris} \cdot \mathrm{HCl}$ pH 8.6, $50 \mu \mathrm{M}$ zinc chloride, $20 \mathrm{mM}$ 1,4-dithio-D,L-threitol (DTT; Thermo Scientific), $8 \mathrm{M}$ urea. They were further purified by ion exchange chromatography (IEC) in a 6-mL Resource Q column (GE Healthcare), previously washed with buffer $\mathrm{G}(20 \mathrm{mM}$ Tris. $\mathrm{HCl} \mathrm{pH} 8.6,0.4 \mathrm{M}$ sodium chloride, $50 \mu \mathrm{M}$ zinc chloride, $1 \mathrm{mM}$ DTT, $8 \mathrm{M}$ urea) and equilibrated with buffer $G$ without sodium chloride. A step gradient of $0 \%, 25 \%, 50 \%$ and $100 \%$ of buffer G was applied and fractions containing protein were pooled. These were then diluted to $0.2 \mathrm{mg} / \mathrm{mL}$ with buffer $50 \mathrm{mM}$ Tris. $\mathrm{HCl} \mathrm{pH} \mathrm{8.6,150} \mathrm{mM} \mathrm{sodium} \mathrm{chloride,} 5 \mathrm{mM}$ calcium chloride, $100 \mu \mathrm{M}$ zinc chloride, $1 \mathrm{mM}$ DTT, $6 \mathrm{M}$ urea, supplemented with cystamine $(20 \mathrm{mM})$ and folded in two consecutive dialysis steps at $4{ }^{\circ} \mathrm{C}$. The first step was performed overnight against a 10 -fold volume excess of buffer $50 \mathrm{mM}$ Tris. $\mathrm{HCl} \mathrm{pH}$ 8.6, $150 \mathrm{mM}$ sodium chloride, $5 \mathrm{mM}$ calcium chloride, $100 \mu \mathrm{M}$ zinc chloride, $5 \mathrm{mM} \beta$-mercaptoethanol, $1 \mathrm{mM}$ 2-hydroxyethyldisulfide. The second step was performed against a 10-fold volume excess of buffer B, twice for 4 hours and then overnight. This procedure caused activation of MMP-14 under removal of the pro-domain. Precipitated protein was removed by centrifugation at $48,000 \times g$ for $30 \mathrm{~min}$ at $4{ }^{\circ} \mathrm{C}$. Subsequently, MMP-14 CD was concentrated and further purified by SEC in a Superdex75 (GE Healthcare) column with buffer B.

Other procedures applied were similar to those of previous publications of the group, e.g. ${ }^{42}$. In particular, protein identities and purities were assessed by 10-14\% Glycine SDS-PAGE gels stained with Coomassie Brilliant Blue, by peptide mass fingerprinting of tryptic protein digests and by $\mathrm{N}$-terminal sequencing through Edman degradation. The latter two analyses were carried out at the Protein Chemistry Service and Proteomics Facilities of the Centro de Investigaciones Biológicas (Madrid, Spain). Ultrafiltration steps were performed with Vivaspin 15, Vivaspin 2 and Vivaspin 500 filter devices of 3-to-30-kDa cutoff (Sartorius Stedim Biotech). Protein concentrations were generally estimated by measuring the $\mathrm{OD}_{280}$ in a spectrophotometer (NanoDrop; GE Healthcare) and applying the respective theoretical extinction coefficients. Particular concentrations were also measured by the BCA Protein Assay Kit (ThermoFisher Scientific) with bovine serum albumin as a standard.

Multi-angle laser light scattering. To determine the real molecular mass of RECK $\Delta \mathrm{C}$, multi-angle laser light scattering (SEC-MALLS) was performed as previously reported ${ }^{42}$ in a Dawn Helios II apparatus (Wyatt Technologies) coupled to a SEC Superdex 200 10/300 Increase column equilibrated in buffer $20 \mathrm{mM}$ Tris· $\mathrm{HCl} \mathrm{pH}$ 
7.4, $150 \mathrm{mM}$ sodium chloride at $25^{\circ} \mathrm{C}$ at the joint IBMB/IRB Crystallography Platform, Barcelona Science Park (Catalonia, Spain). ASTRA 7 software (Wyatt Technologies) was used for data processing and analysis, for which a typical $\mathrm{dn} / \mathrm{dc}$ value for proteins $(0.185 \mathrm{~mL} / \mathrm{g})$ was assumed. All experiments were performed in triplicate.

Proteolytic inhibition assays. Inhibition assays with fluorogenic protein and peptide substrates were performed in a microplate fluorimeter (Infinite M200, TECAN) in $100 \mu \mathrm{L}$ reaction volumes. Proteolytic activity of MMP-2, MMP-7 and MMP-9 (all from R\&D Systems) was measured with the fluorescence-based EnzCheck Assay Kit containing DQ Gelatin $\left(\lambda_{\mathrm{ex}}=490 \mathrm{~nm}\right.$ and $\left.\lambda_{\mathrm{em}}=520 \mathrm{~nm}\right)$ as fluorescein conjugate (Invitrogen) at $12.5 \mu \mathrm{g} / \mathrm{mL}$. Peptidolytic activity of MMP-14 CD was measured with the fluorogenic substrate FS-6 (Mca-K-P-L-G-L-Dnp-Dpa-A-R-NH ${ }_{2} ; \lambda_{\mathrm{ex}}=325 \mathrm{~nm}$ and $\lambda_{\mathrm{em}}=400 \mathrm{~nm}$; Sigma) at $5 \mu \mathrm{M}$. Reactions were

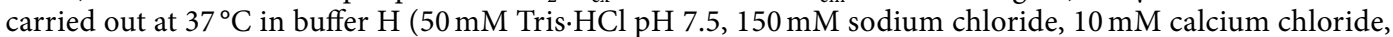
$50 \mu \mathrm{M}$ zinc chloride, $0.05 \%$ Brij-35) except for MMP-2 and MMP-7, for which buffer $\mathrm{H}$ supplemented with $1 \mathrm{mM}$ 4-aminophenylmercuric acetate (APMA, Sigma) was used to activate the respective zymogens by incubation for $1 \mathrm{~h}$ at $37^{\circ} \mathrm{C}$. Inhibition was measured after preincubation of a 2-, 5-, 10-, 50- and 100-fold molar excess of tester proteins (KL23, KL123, RECK $\Delta$ C, FRAG-1 and N-TES) with MMP-2 (0.35 ng), MMP-7 (9.8 ng), MMP-9 (2.5 ng) or MMP-14 CD (50 ng) for $1 \mathrm{~h}$ at $37^{\circ} \mathrm{C}$. Substrates were added to the reaction mixture and the residual proteolytic activity was measured over a timespan of $3 \mathrm{~h}$. Relative activities of MMP-2, MMP-7 and MMP-9 against fluorogenic protein substrates were determined from the slope of a fluorescence vs. time curve. In contrast, fluorogenic peptides were cleaved too fast for proper slope determination, so the relative activity of MMP-14 in front of FS- 6 was determined from the absolute fluorescence values measured between 40 and 50 min after reaction start. Control activity of KL23, KL123, RECK $\Delta$ C, FRAG-1, N-TES and BSA was measured between 110 and 120 min after reaction start. Bovine serum albumin (BSA; Sigma) at 100-fold molar excess and o-phenanthroline (Fluka) at $5 \mathrm{mM}$ were included as negative and positive controls for inhibition, respectively. In addition, inhibition assays against cleavage of human plasma fibronectin ( $\mathrm{pFN}$, MP Biomedicals) were evaluated by Western blot analysis (see below). MMP-2 or MMP-7 (at $40 \mathrm{nM}$ ) were incubated in buffer $\mathrm{H}$ plus $1 \mathrm{mM}$ APMA for activation with pFN $(4 \mathrm{nM})$ at $37^{\circ} \mathrm{C}$ for $0,1,2,4,6,8$ or $18 \mathrm{~h}$ with or without RECK $\Delta \mathrm{C}(400 \mathrm{nM})$. The broad-spectrum MMP inhibitors marimastat (Sigma), EDTA (Fluka), o-phenanthroline, and batimastat (Calbiochem) were used in controls, as well as the serine peptidase inhibitors AEBSF and phenylmethanesulfonyl fluoride (PMSF; Acros Organics) plus the cOmplete EDTA-Free inhibitor cocktail.

Western blot analyses. Protein samples were separated by $10 \%$ Glycine SDS-PAGE, transferred to Amersham Protran Premium NC Nitrocellulose Membranes (GE Healthcare Life Sciences) and blocked for one hour under gentle stirring at room temperature with $50 \mathrm{~mL}$ of blocking solution $(5 \%$ BSA in phosphate buffered saline [PBS] plus $0.2 \%$ Tween 20 [PBS-T]; Sigma). Fibronectin was detected by overnight incubation at $4{ }^{\circ} \mathrm{C}$ with a rabbit polyclonal primary antibody (Abcam) diluted 1:5,000 in PBS-T with 1\% BSA and subsequent incubation for $2 \mathrm{~h}$ at room temperature with an anti-rabbit HRP-conjugated secondary antibody (Sigma) diluted 1:8,000 with PBS-T. Blots were incubated with mild stripping buffer (1.5\% glycine $\mathrm{pH} 2.2,0.1 \%$ SDS, $1 \%$ Tween 20 ) and further washed with PBS and PBS-T under gentle agitation at room temperature. Blots were re-blocked and re-probed.

$\mathrm{His}_{6}$-tagged proteins were detected with the monoclonal His-HRP Conjugated Antibody (Santa Cruz Biotechnology) diluted 1:5,000 in PBS-T with 1\% BSA incubated overnight at $4{ }^{\circ} \mathrm{C}$ and subsequently visualized with an enhanced chemiluminescence system (Super Signal West Pico Chemiluminescent; Pierce) according to the manufacturer's instructions. Membranes were exposed to Hyperfilm ECL films (GE Healthcare Life Sciences).

Miscellaneous. Structure prediction calculations through threading were performed with LOMETS ${ }^{43}$ and RAPTORX $^{44}$ with standard parameters.

\section{Results and Discussion}

Protein preparation. Inhibitory activity of RECK on MMPs in vitro has been reported for RECK $\Delta \mathrm{C}^{13-15,17,23}$ and a construct spanning the KL2 and KL3 domains ${ }^{16}$. As there were discrepancies in the boundaries of these domains ${ }^{13,16}$, we performed structure prediction through threading of segment $\mathrm{V}^{600}-\mathrm{A}^{800}$. These calculations suggested that constructs KL123 and KL23 should actually span segments $\mathrm{V}^{621}-\mathrm{S}^{797}$ and $\mathrm{T}^{697}-\mathrm{S}^{797}$, respectively (Fig. 1), which do not contain any of the glycosylation sites of the full-length protein ${ }^{22}$. Follistatin (Protein Data Bank [PDB] entries 2P6A, 3HH2 and 2B0U), a regulator of ligands of the transforming growth factor- $\beta$ superfamily with three Kazal-like repeats ${ }^{45}$, and follistatin-like protein 3 (PDB 3B4V) were identified as the closest structural relatives. Both RECK constructs were produced with C-terminal His ${ }_{6}$-tags overnight in E. coli Lemo21 cells at room temperature and translocated to the periplasm, which provides an oxidizing environment for the formation of disulphide bonds and protein folding. The proteins were obtained in high yields as nonclassical inclusion bodies ${ }^{46}$, which were treated under non-reducing conditions with a chaotropic agent and detergent prior to purification by AC and SEC steps (Fig. 2A-D). The resulting proteins were soluble and highly pure, did not aggregate when concentrated, and migrated according to $16 \mathrm{kDa}$ (KL23) and $26 \mathrm{kDa}$ (KL123) in calibrated SEC (data not shown), which are consistent with monomeric species. These data suggest that the proteins were well-folded.

We also isolated RECK $\Delta \mathrm{C}$ with a C-terminal $\mathrm{His}_{6}$-tag (Fig. 1) from the conditioned medium of transiently transfected Expi cells by adapting a protocol developed previously for human $\alpha_{2}$-macroglobulin ${ }^{42}$. The yield after purification was $0.8 \mathrm{mg}$ per litre of expression medium, and the protein was subsequently purified by AC and SEC (Fig. 2E). It had a molecular mass of $111 \mathrm{kDa}$ according to SEC-MALLS (Fig. 2F), which is in good agreement with the theoretical protein mass plus glycosylation, and indicates that the protein is monomeric. This contrasts with other studies postulating it is a dimer ${ }^{17}$. We further produced RECK $\Delta \mathrm{C}$ from S2 and Expi-CHO systems but the initial yields were significantly lower $(0.2$ and $0.5 \mathrm{mg} / \mathrm{L}$, respectively) and the proteins required several 

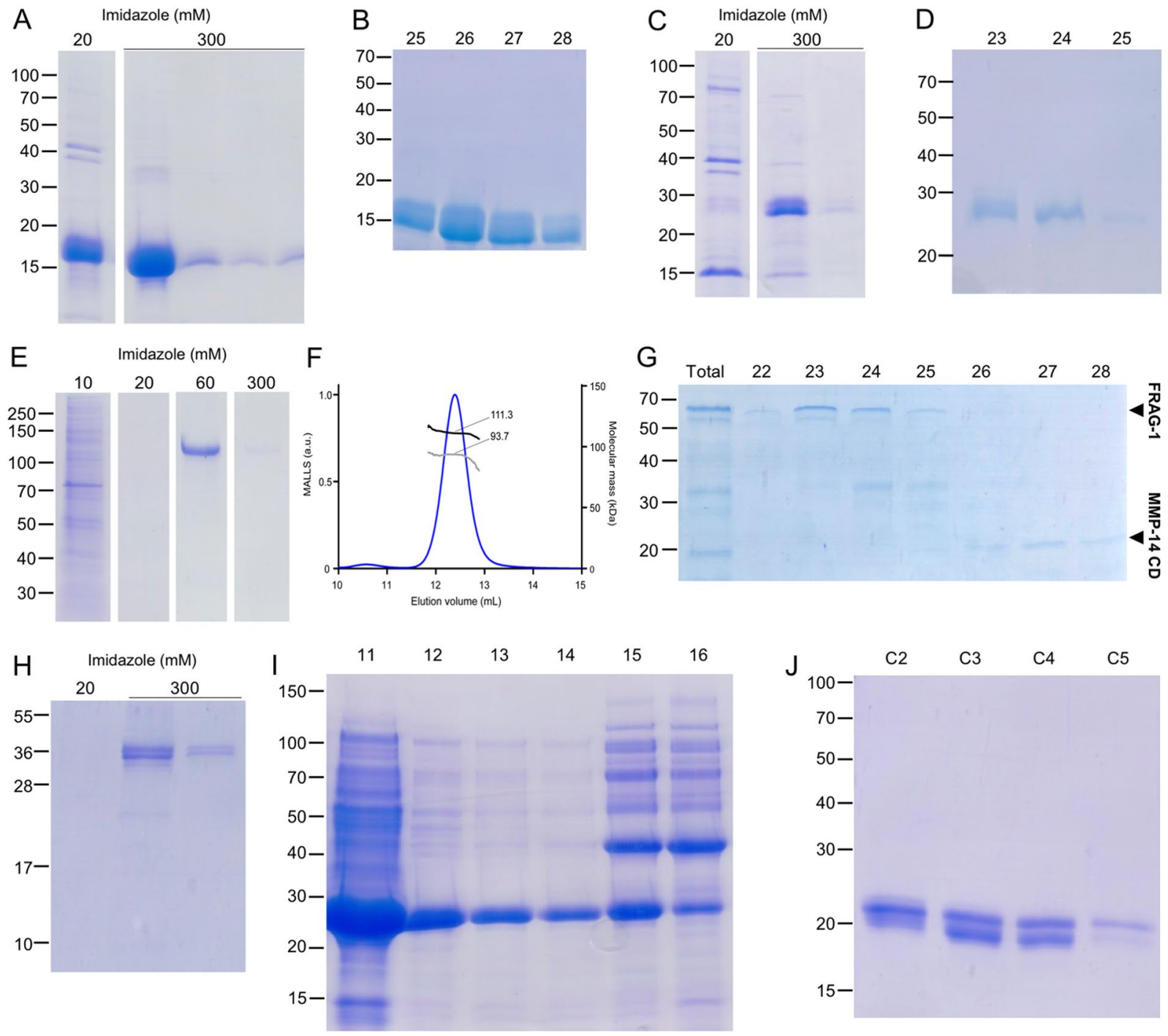

Figure 2. Protein purification. SDS-PAGE of AC and SEC purification steps of KL23 (A,B) and KL123 (C,D). (E) SDS-PAGE of stepwise AC of RECK $\Delta \mathrm{C}$ from Expi cells. (F) SEC-MALLS chromatogram of RECK $\Delta \mathrm{C}$ showing it has a total molecular mass of $111.3 \mathrm{kDa}$ of which $93.7 \mathrm{kDa}$ would correspond to protein. (G) SDSPAGE of SEC fractions containing FRAG-1 (22-25) and MMP-14 CD (26-28). (H) SDS-PAGE of partially purified N-TES after AC purification. (I) SDS-PAGE of AEC purification of MMP-14 CD. (J) SDS-PAGE of the SEC fractions containing MMP-14 CD (C2-C5). MMP-14 CD migrates as two bands as previously observed for construct MT1Cat in ${ }^{41}$. Figure panels with lanes/parts from different gels/blots show white separation lines. All original gels can be found in the supplementary materials.

additional purification steps (data not shown). We next obtained N-TES by the same method from transfected Expi cells (Fig. 2H). This protein spans the $\mathrm{N}$-terminal region of the calcium-binding proteolgycan testican 3, which has been reported to bind membrane-type MMPs including MMP-14 and to inhibit pro-MMP-2 activation in HEK293T cells when their respective cDNAs were co-transfected. These results led the authors to suggest that $\mathrm{N}-\mathrm{TES}$ is an inhibitor of MMP-14 and MMP- $16^{47}$.

Finally, we also produced and purified RECK fragment FRAG-1 resulting from the limited cleavage of RECK $\triangle \mathrm{C}$ by MMP-14 CD, which contained the C-terminal half of the full-length protein including KL1 through KL3 (Figs. 1 and 2G). MMP-14 CD was produced by E. coli BL21 (DE3) in inclusion bodies, purified by IEC under denaturing conditions, folded by dialysis, and finally purified by SEC by implementing a previous proto$\operatorname{col}^{41}$ (Fig. 2I,J).

Proteolytic contamination and additional purification steps. Recombinant RECK $\Delta \mathrm{C}$ from Expi cells was initially purified by AC (Fig. 2E) and SEC. Despite rather high purity (>98\%; Figs. 2E and 3A), it underwent cleavage over time, which was prevented by an inhibitor cocktail and partially slowed down by the general zinc chelator and MP inhibitor o-phenanthroline (Fig. 3A). However, this cleavage did not result in dissociation of RECK $\triangle \mathrm{C}$ in the short term, according to SEC. The cleavage products caused by this impurity (Fig. 3A, lane 2) were subjected to $\mathrm{N}$-terminal Edman degradation, which revealed that a $\sim 50-\mathrm{kDa}$ fragment, 

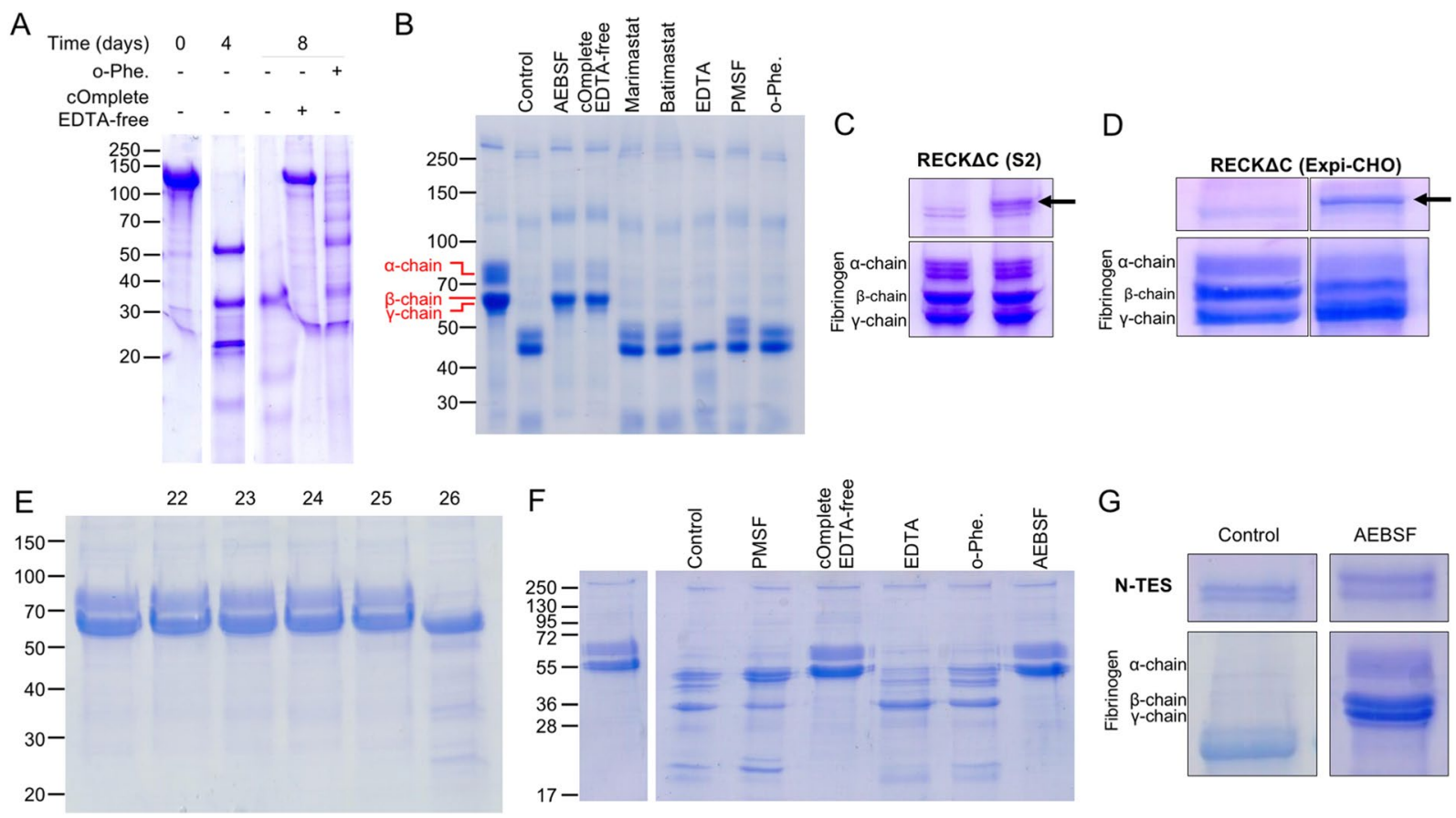

Figure 3. Functional assays. (A) Partially purified RECK $\Delta \mathrm{C}$ incubated for up to 8 days at $37^{\circ} \mathrm{C}$ with or without o-phenanthroline (o-Phe.) or an inhibitor cocktail (cOmplete EDTA-free). (B) Degradation of fibrinogen. Lane 1 , intact fibrinogen; lane 2, control, fibrinogen incubated with partially purified RECK $\Delta \mathrm{C}$ for two days shows degradation; lanes 3-9, same except for a previous one hour-incubation of RECK $\Delta \mathrm{C}$ with AEBSF, inhibitor cocktail, marimastat, batimastat, EDTA, PMSF or o-phenanthroline. Fibrinogen cleavage does not occur with similarly purified RECK $\Delta$ C from (C) S2 cells or (D) Expi-CHO cells (both, left lane, fibrinogen alone; right lane, fibrinogen plus RECK $\Delta \mathrm{C}$ [black arrow]). (E) Incubation of fibrinogen (lane 1, control) with SEC fractions containing only FRAG-1 (22-25) show no degradation. However, the substrate is cleaved by a coeluting MMP$14 \mathrm{CD}$ contamination (fraction 26). (F) Incubation of fibrinogen (lane 1) with partially purified N-TES without (lane 2, control) or with (lanes 3-7) inhibitors. (G) An N-TES preparation purified by SEC cleaved fibrinogen (control). This cleavage was abolished with AEBSF. Figure panels with lanes/parts from different gels/blots show white separation lines. All original gels can be found in the supplementary materials.

dubbed FRAG-1, resulted from cleavage before $\mathrm{G}^{484}$ and thus comprised RECK domains KL1-KL2-KL3. As partially purified RECK $\triangle \mathrm{C}$ had initially shown slight inhibition of MMP-14 CD (data not shown), we speculated that RECK $\triangle \mathrm{C}$ cleavage might be necessary to yield a species with MMP inhibitory activity. Thus, we included FRAG-1 in subsequent inhibition assays (see below).

To investigate the nature of the proteolytic impurity, we incubated initially purified RECK $\Delta \mathrm{C}$ with the general peptidase substrate human plasma fibrinogen, and found it was cleaved (Fig. 3B). We assayed a series of peptidase inhibitors and found that AEBSF abolished cleavage (Fig. 3B). AEBSF is an irreversible small-molecule serine peptidase inhibitor that covalently modifies the catalytic serine of serine endopeptidases, thus blocking them. The same ablation was obtained with the inhibitor cocktail, which contained AEBSF, but not with PMSF or general MP inhibitors (Fig. 3B). This motivated us to include an extra step in the purification protocol of RECK $\triangle \mathrm{C}$ from Expi cells consisting of incubation with AEBSF and final polishing by several cycles of SEC. This protocol yielded RECK $\Delta \mathrm{C}$ of highest purity, incapable of fibrinogen or RECK $\Delta \mathrm{C}$ degradation, for subsequent inhibitory studies. Interestingly, protein produced from S2 or Expi-CHO cells did not show this contaminant and fibrinogen remained intact upon incubation with these RECK $\Delta$ C species (Fig. 3C,D). Finally, FRAG-1 obtained from highly pure RECK $\triangle \mathrm{C}$ through treatment with MMP-14 CD did not contain the proteolytic contaminant of partially purified RECK $\triangle \mathrm{C}$ but some traces of the MP, which could be separated in SEC (Fig. 3E).

To assess whether the AEBSF-sensitive contaminant was a specific feature of the overexpression of RECK $\Delta \mathrm{C}$, we studied protein N-TES obtained with the same expression system (Fig. $2 \mathrm{H}$ ) and observed similar peptidolytic activity against fibrinogen that was abolished with AEBSF or the inhibitor cocktail (Fig. 3F,G). In contrast, two other proteins obtained with the same system did not contain this contaminant (data not shown).

Inhibition studies of RECK and N-TES constructs. Highly pure RECK variants RECK $\triangle \mathrm{C}, \mathrm{KL} 123, \mathrm{KL} 23$ and FRAG-1, as well as N-TES, were tested for their inhibitory capacity against MMP-2, MMP-7, MMP-9 and MMP-14 activity with peptide and protein substrates up to 100-fold molar excess of the tester proteins (Figs. 4 and 5). Fluorescein-conjugated gelatine was used for assays with previously activated MMP-2 (Fig. 4B), MMP-7 (Fig. 4C) and MMP-9 (Fig. 4D), and fluorogenic peptide FS-6 was employed for MMP14 CD (Fig. 4E). In addition, inhibition of the activity of MMP-2 (Fig. 5A) and MMP-7 (Fig. 5B) against plasma fibronectin by RECK $\triangle \mathrm{C}$ at tenfold molar excess was assayed by Western blot analysis. Moreover, inhibition of the activity of MMP-14 CD 
A

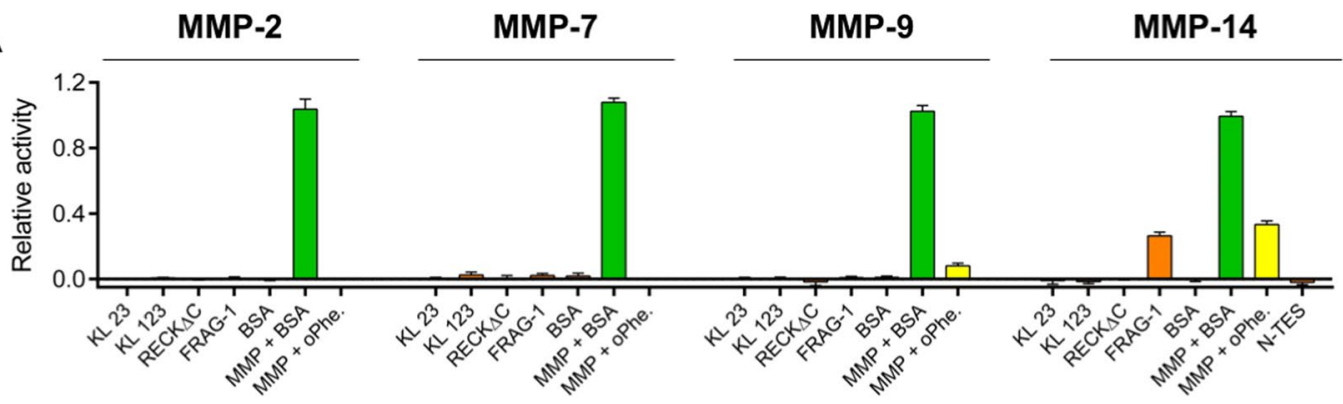

KL 23

KL 123
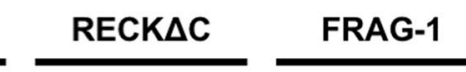

N-TES

B

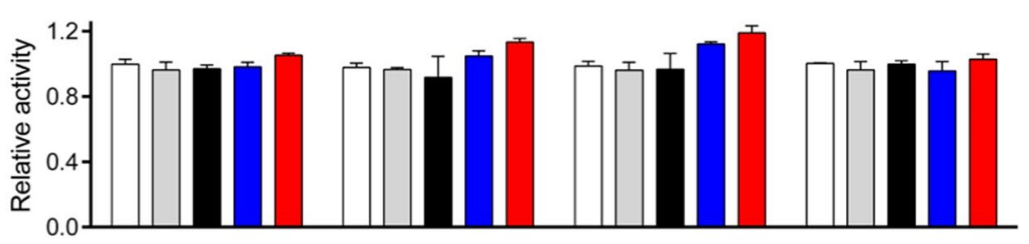

C

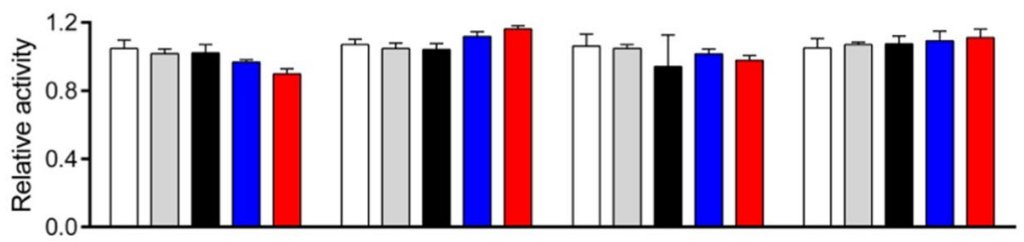

D

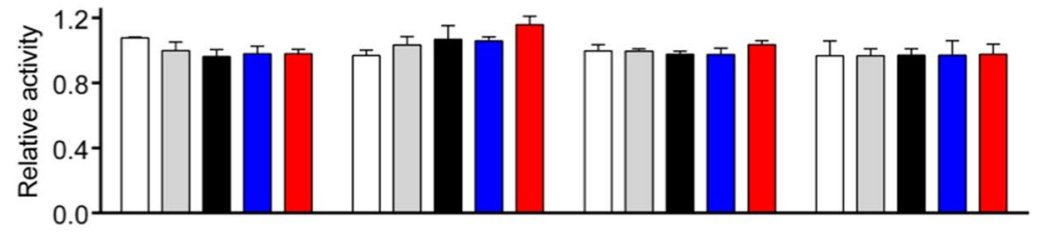

$\mathrm{E}$

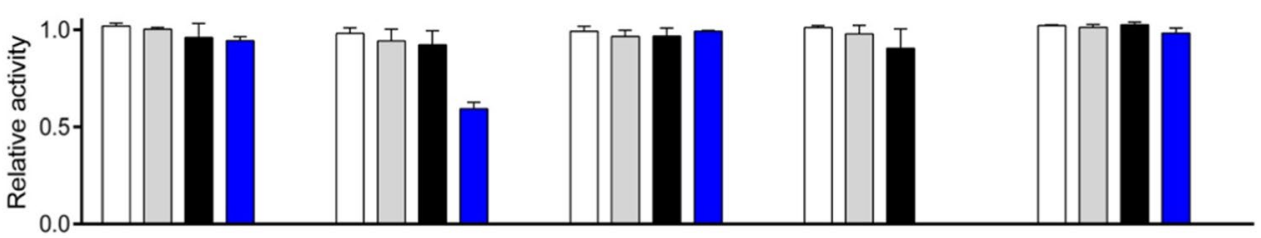

Tested proteins

$\mathrm{MMP}+\mathrm{BSA}$

$\mathrm{MMP}+\mathrm{oPhe}$

2

5

$10 \square 50$

Figure 4. Activity and inhibition assays. (A) Hydrolytic activity of pure RECK constructs, N-TES and BSA (tested proteins, orange bars) relative to that of the respective MMPs (MMP-2, -7, -9 and -14) with BSA (100\%; positive control, green bar) or o-phenantroline (negative control, yellow bar). Only FRAG-1 evinces slight residual activity against the fluorogenic substrate FS-6, possibly due to a contamination with MMP-14 CD used for its generation (see Fig. 2G). (B) Residual activity of MMP-2 in the presence of KL23, KL123, RECK $\Delta$ C or FRAG-1 at various molar rations (1:2, 1:5, 1:10, 1:50 and 1:100; white, gray, black blue and red bars) after $1 \mathrm{~h}$ incubation relative to the activity shown in (A; green bar). (C) and (D), same as (A) for MMP-7 and MMP-9. (E) Same as (A) for MMP-14 but further including N-TES as candidate inhibitor up to 1:50 molar ratio. Only 50 -fold excess of KL123 shows a slight inhibitory effect on MMP-14 CD activity. All assays of panels A-E were performed in triplicate.

against a fluorogenic peptide substrate by N-TES was likewise analysed (Fig. 4E). As expected, none of the RECK constructs, N-TES or BSA, which was used as a negative control, alone showed relevant peptidolytic activity and o-phenanthroline inhibited the MMPs (Fig. 4A). In addition, BSA at the highest tester concentration (1:100 molar excess) had no influence on MMP activity (Fig. 4A). Notably, the experiments revealed that none of the RECK constructs or N-TES showed any significant inhibition of MMPs activity.

Conclusions. Since its discovery in the 1980s, protein RECK has been found to have pleiotropic roles, for example in embryogenesis and as a tumour suppressor. Among other functions, it has been hailed as an MMP inhibitor. Here, we produced two RECK variants through the mammalian Expi and Expi-CHO systems and through the insect S2 system. We could not detect any significant inhibition with either construct produced with Expi when we assayed 

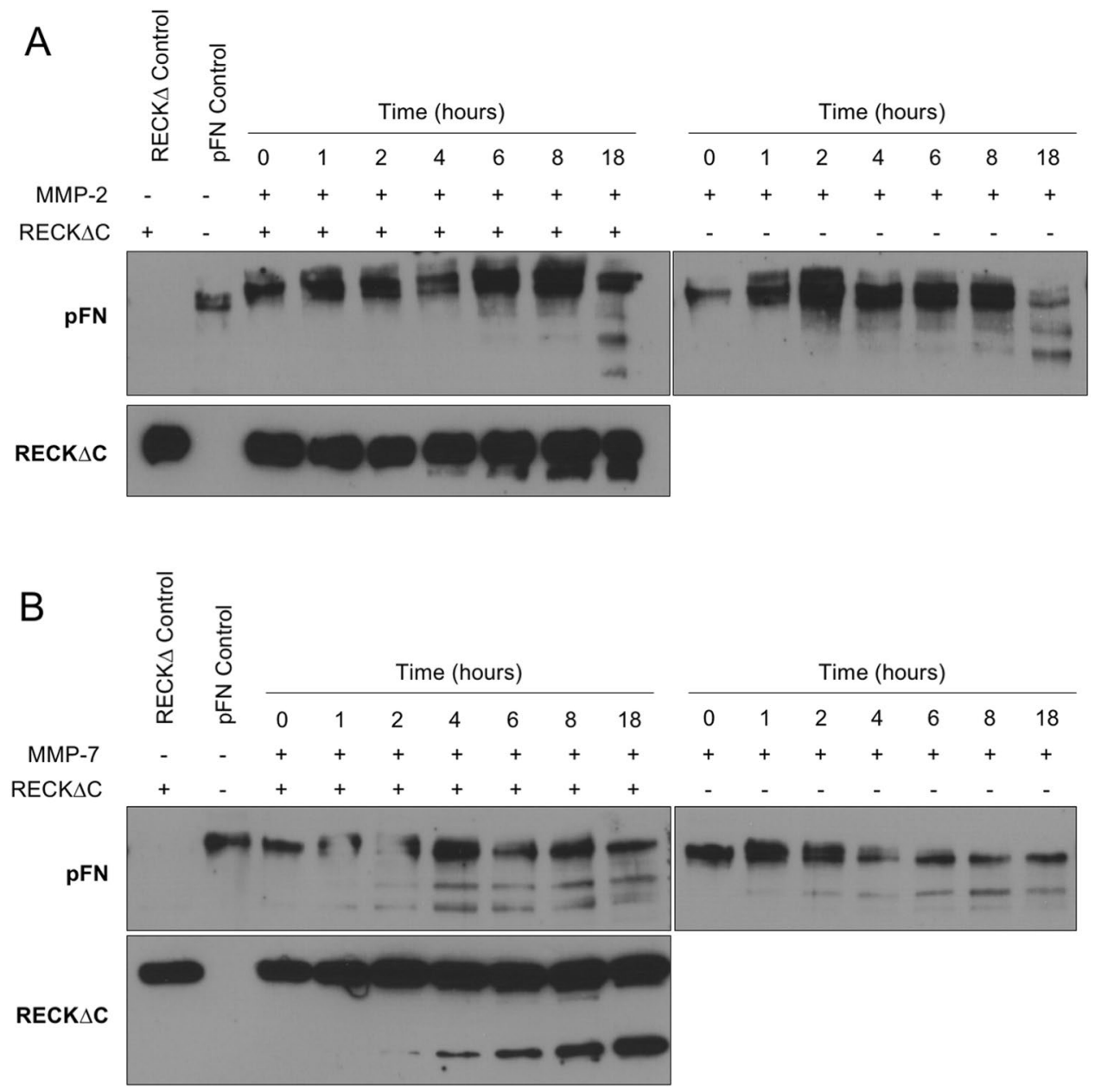

Figure 5. MMP-2 and MMP-7 activity assays against plasma fibronectin. (A) Western-blot analysis of the MMP-2 (40 nM) activity in front of plasma fibronectin ( $\mathrm{pFN} ; 4 \mathrm{nM})$ in the presence or absence of RECK $\Delta \mathrm{C}$ $(400 \mathrm{nM})$ over time $(0-18 \mathrm{~h})$. The peptidase eventually cleaves the substrate irrespective of the presence of RECK $\Delta$ C. (B) Same as (A) for MMP-7. In addition, MMP-7 cleaves RECK $\Delta$ C over time. Figure panels with lanes/parts from different gels/blots show white separation lines. All original gels can be found in the supplementary materials.

MMPs that have been previously reported to be targeted, neither with peptide nor protein substrates. Instead, we found that even quite pure samples of RECK $\Delta \mathrm{C}$ showed proteolytic activity resulting from a contamination by a probable serine peptidase, which could be removed by treatment with AEBSF and additional SEC. This activity was missing when the protein was produced in Expi-CHO or S2 cells. We further established a production and purification protocol for N-TES, which has also been postulated to be an MMP inhibitor. As in the case of RECK, we detected the contaminating peptidase but no inhibitory activity in front of the target MMP-14. In contrast, similar expression systems for two other unrelated proteins did not produce the contaminant in the supernatant. Finally, we made two shorter constructs of RECK spanning KL1-KL2-KL3 and KL2-KL3, respectively, through an E. coli system, which also lacked the contaminant. These proteins did not show any inhibitory effect on MMPs either.

These results are consistent with marginal notes in a recent article describing very sensitive gelatine zymography, which revealed gelatinolytic activity associated with recombinant RECK $\Delta \mathrm{C}$ preparations ${ }^{23}$. These corresponded to co-purified peptidases of $\sim 19$ and $\sim 28 \mathrm{kDa}$, which necessarily must have perturbed previously published kinetic assays with partially purified RECK $\Delta \mathrm{C}$ from supernatants of transfected $293 \mathrm{~F}$ and $293 \mathrm{~T}$ cells, as well as construct K23 from 293 T cells, for which inhibitory activity on MMPs had been reported ${ }^{13,15-17}$. Moreover, the inhibitory activity of RECK on MMPs was requalified as "weak" recently ${ }^{36}$.

Taken together, all these findings suggest that RECK, and probably N-TES, are not direct inhibitors of MMP catalytic activity. Instead, RECK may still regulate MMPs in vivo at a different level, e.g. through downregulation of MMP transcription, translation or secretion, or by binding and sequestering them, thus preventing them from carrying out their extracellular peptidolytic function.

Finally, we recommend checking for unexpected proteolytic activity associated with recombinant proteins of interest when employing transfected Expi293F or other HEK293-derived cells as protein expression systems. This activity can be removed through irreversible serine peptidase inhibitors and is absent from systems based on Chinese hamster ovary or fruit-fly S2 cells. 
Received: 8 January 2020; Accepted: 30 March 2020;

Published online: 14 April 2020

\section{References}

1. Cerdà-Costa, N. \& Gomis-Rüth, F. X. Architecture and function of metallopeptidase catalytic domains. Prot. Sci. 23, 123-144, https://doi.org/10.1002/pro.2400 (2014).

2. Edwards, D. R., Handsley, M. M. \& Pennington, C. J. The ADAM metalloproteinases. Mol. Aspects Med. 29, 258-289, https://doi. org/10.1016/j.mam.2008.08.00 (2008).

3. Murphy, G. \& Nagase, H. Progress in matrix metalloproteinase research. Mol. Aspects Med. 29, 290-308, https://doi.org/10.1016/j. mam.2008.05.002 (2008).

4. Apte, S. S. A disintegrin-like and metalloprotease (reprolysin-type) with thrombospondin type 1 motif (ADAMTS) superfamily: functions and mechanisms. J. Biol. Chem. 284, 31493-31497, https://doi.org/10.1074/jbc.R109.052340 (2009).

5. Tallant, C., Marrero, A. \& Gomis-Rüth, F. X. Matrix metalloproteinases: fold and function of their catalytic domains. Biochim. Biophys. Acta - Mol. Cell Res. 1803, 20-28, https://doi.org/10.1016/j.bbamcr.2009.04.003 (2010).

6. Jobin, P. G., Butler, G. S. \& Overall, C. M. New intracellular activities of matrix metalloproteinases shine in the moonlight. Biochim. Biophys. Acta - Mol. Cell Res. 1864, 2043-2055, https://doi.org/10.1016/j.bbamcr.2017.05.013 (2017).

7. Klein, T., Eckhard, U., Dufour, A., Solis, N. \& Overall, C. M. Proteolytic cleavage-mechanisms, function, and "omic" approaches for a near-ubiquitous posttranslational modification. Chem. Rev. 118, 1137-1168, https://doi.org/10.1021/acs.chemrev.7b00120 (2018).

8. Arolas, J. L., Goulas, T., Cuppari, A. \& Gomis-Rüth, F. X. Multiple architectures and mechanisms of latency in metallopeptidase zymogens. Chem. Rev. 118, 5581-5597, https://doi.org/10.1021/acs.chemrev.8b00030 (2018).

9. Katunuma, N. Regulation of intracellular enzyme levels by limited proteolysis. Rev. Physiol. Biochem. Pharmacol. 72, 83-104, https:// doi.org/10.1007/bfb0031547 (1975).

10. Tortorella, M. D. et al. $\alpha_{2}$-Macroglobulin is a novel substrate for ADAMTS-4 and ADAMTS-5 and represents an endogenous inhibitor of these enzymes. J. Biol. Chem. 279, 17554-17561, https://doi.org/10.1074/jbc.M313041200 (2004).

11. Nagase, H., Visse, R. \& Murphy, G. Structure and function of matrix metalloproteinases and TIMPs. Cardiovasc. Res. 69, 562-573, https://doi.org/10.1016/j.cardiores.2005.12.002 (2006).

12. Goulas, T. et al. Structural and functional insight into pan-endopeptidase inhibition by $\alpha 2$-macroglobulins. Biol. Chem. 398, 975-994, https://doi.org/10.1515/hsz-2016-0329 (2017).

13. Takahashi, C. et al. Regulation of matrix metalloproteinase- 9 and inhibition of tumor invasion by the membrane-anchored glycoprotein RECK. Proc. Natl. Acad. Sci. USA 95, 13221-13226, https://doi.org/10.1073/pnas.95.22.13221 (1998).

14. Oh, J. et al. The membrane-anchored MMP inhibitor RECK is a key regulator of extracellular matrix integrity and angiogenesis. Cell 107, 789-800, https://doi.org/10.1016/s0092-8674(01)00597-9 (2001).

15. Miki, T. et al. The reversion-inducing cysteine-rich protein with Kazal motifs (RECK) interacts with membrane type 1 matrix metalloproteinase and CD13/aminopeptidase $\mathrm{N}$ and modulates their endocytic pathways. J. Biol. Chem. 282, 12341-12352, https:// doi.org/10.1074/jbc.M610948200 (2007).

16. Chang, C. K., Hung, W. C. \& Chang, H. C. The Kazal motifs of RECK protein inhibit MMP-9 secretion and activity and reduce metastasis of lung cancer cells in vitro and in vivo. J. Cell. Mol. Med. 12, 2781-2789, https://doi.org/10.1111/j.1582-4934.2008.00215.x (2008).

17. Omura, A. et al. RECK forms cowbell-shaped dimers and inhibits matrix metalloproteinase-catalyzed cleavage of fibronectin. J. Biol. Chem. 284, 3461-3469, https://doi.org/10.1074/jbc.M806212200 (2009).

18. Noda, M. et al. Detection of genes with a potential for suppressing the transformed phenotype associated with activated ras genes. Proc. Natl. Acad. Sci. USA 86, 162-166, https://doi.org/10.1073/pnas.86.1.162 (1989).

19. Kazal, L. A., Spicer, D. S. \& Brahinsky, R. A. Isolation of a crystalline trypsin inhibitor-anticoagulant protein from pancreas. J. Am. Chem. Soc. 70, 3034-3040, https://doi.org/10.1021/ja01189a060 (1948).

20. Laskowski, M. Jr. \& Kato, I. Protein inhibitors of proteinases. Annu. Rev. Biochem. 49, 593-626, https://doi.org/10.1146/annurev. bi.49.070180.003113 (1980)

21. Rhee, J. S. \& Coussens, L. M. RECKing MMP function: implications for cancer development. Trends Cell Biol. 12, 209-211, https:// doi.org/10.1016/s0962-8924(02)02280-8 (2002).

22. Simizu, S., Takagi, S., Tamura, Y. \& Osada, H. RECK-mediated suppression of tumor cell invasion is regulated by glycosylation in human tumor cell lines. Cancer Res. 65, 7455-7461, https://doi.org/10.1158/0008-5472.CAN-04-4446 (2005).

23. Muraguchi, T. et al. RECK modulates Notch signaling during cortical neurogenesis by regulating ADAM10 activity. Nat. Neurosci. 10, 838-845, https://doi.org/10.1038/nn1922 (2007).

24. Willson, J. A. \& Damjanovski, S. Spatial analysis of RECK, MT1-MMP, and TIMP-2 proteins during early Xenopus laevis development. Gene Expr. Patterns 34, 119066, https://doi.org/10.1016/j.gep.2019.119066 (2019).

25. Vanhollebeke, B. et al. Tip cell-specific requirement for an atypical Gpr124-and Reck-dependent Wnt/beta-catenin pathway during brain angiogenesis. Elife 4, e06489, https://doi.org/10.7554/eLife.06489 (2015).

26. Li, H. et al. RECK in neural precursor cells plays a critical role in mouse forebrain angiogenesis. iScience 19, 559-571, https://doi. org/10.1016/j.isci.2019.08.009 (2019).

27. Cho, C., Wang, Y., Smallwood, P. M., Williams, J. \& Nathans, J. Molecular determinants in Frizzled, Reck, and Wnt7a for ligandspecific signaling in neurovascular development. Elife 8, e47300, https://doi.org/10.7554/eLife.47300 (2019).

28. Hill, V. K. et al. Genome-wide DNA methylation profiling of CpG islands in breast cancer identifies novel genes associated with tumorigenicity. Cancer Res. 71, 2988-2999, https://doi.org/10.1158/0008-5472.CAN-10-4026 (2011).

29. Yoshida, Y., Ninomiya, K., Hamada, H. \& Noda, M. Involvement of the SKP2-p27(KIP1) pathway in suppression of cancer cell proliferation by RECK. Oncogene 31, 4128-4138, https://doi.org/10.1038/onc.2011.570 (2012).

30. Masui, T. et al. RECK expression in pancreatic cancer: its correlation with lower invasiveness and better prognosis. Clin. Cancer Res. 9, 1779-1784 (2003).

31. Span, P. N. et al. Matrix metalloproteinase inhibitor reversion-inducing cysteine-rich protein with Kazal motifs: a prognostic marker for good clinical outcome in human breast carcinoma. Cancer 97, 2710-2715, https://doi.org/10.1002/cncr.11395 (2003).

32. Takenaka, K. et al. Expression of a novel matrix metalloproteinase regulator, RECK, and its clinical significance in resected nonsmall cell lung cancer. Eur. J. Cancer 40, 1617-1623, https://doi.org/10.1016/j.ejca.2004.02.028 (2004).

33. Kang, H. G. et al. RECK expression in osteosarcoma: correlation with matrix metalloproteinases activation and tumor invasiveness. J. Orthop. Res. 25, 696-702, https://doi.org/10.1002/jor.20323 (2007).

34. Chen, R., Sheng, L., Zhang, H. J., Ji, M. \& Qian, W. Q. miR-15b-5p facilitates the tumorigenicity by targeting RECK and predicts tumour recurrence in prostate cancer. J. Cell Mol. Med. 22, 1855-1863, https://doi.org/10.1111/jcmm.13469 (2018).

35. Chen, H. C. et al. Prognostic role of RECK in pathological outcome-dependent buccal mucosa squamous cell carcinoma. Oral Dis. 25, https://doi.org/10.1111/odi.13214, https://doi.org/10.1111/odi.13214 (2019).

36. Matsuzaki, T. et al. The RECK tumor-suppressor protein binds and stabilizes ADAMTS10. Biol. Open 7, bio033985, https://doi. org/10.1242/bio.033985 (2018).

37. Rawlings, N. D. et al. The MEROPS database of proteolytic enzymes, their substrates and inhibitors in 2017 and a comparison with peptidases in the PANTHER database. Nucleic Acids Res. 46, D624-D632, https://doi.org/10.1093/nar/gkx1134 (2018). 
38. Goulas, T. et al. The pCri System: a vector collection for recombinant protein expression and purification. PloS one 9, e112643, https://doi.org/10.1371/journal.pone.0112643 (2014).

39. van den Ent, F. \& Löwe, J. RF cloning: a restriction-free method for inserting target genes into plasmids. J. Biochem. Biophys. Methods 67, 67-74, https://doi.org/10.1016/j.jbbm.2005.12.008 (2006).

40. Woskowicz, A. M., Weaver, S. A., Shitomi, Y., Ito, N. \& Itoh, Y. MT-LOOP-dependent localization of membrane type I matrix metalloproteinase (MT1-MMP) to the cell adhesion complexes promotes cancer cell invasion. J. Biol. Chem. 288, 35126-35137, https://doi.org/10.1074/jbc.M113.496067 (2013).

41. Itoh, Y. et al. Homophilic complex formation of MT1-MMP facilitates proMMP-2 activation on the cell surface and promotes tumor cell invasion. EMBO J. 20, 4782-4793, https://doi.org/10.1093/emboj/20.17.4782 (2001).

42. Marino-Puertas, L., Del Amo-Maestro, L., Taules, M., Gomis-Rüth, F. X. \& Goulas, T. Recombinant production of human $\alpha 2-$ macroglobulin variants and interaction studies with recombinant G-related $\alpha 2$-macroglobulin binding protein and latent transforming growth factor-32. Sci. Rep. 9, 9186, https://doi.org/10.1038/s41598-019-45712-z (2019).

43. Wu, S. \& Zhang, Y. LOMETS: a local meta-threading-server for protein structure prediction. Nucleic Acids Res. 35, 3375-3382, https://doi.org/10.1093/nar/gkm251 (2007).

44. Källberg, M. et al. Template-based protein structure modeling using the RaptorX web server. Nat. Protoc. 7, 1511-1522, https://doi. org/10.1038/nprot.2012.085 (2012)

45. Lerch, T. F., Shimasaki, S., Woodruff, T. K. \& Jardetzky, T. S. Structural and biophysical coupling of heparin and activin binding to follistatin isoform functions. J. Biol. Chem. 282, 15930-15939, https://doi.org/10.1074/jbc.M700737200 (2007).

46. Jevsevar, S. et al. Production of nonclassical inclusion bodies from which correctly folded protein can be extracted. Biotechnol. Prog. 21, 632-639, https://doi.org/10.1021/bp0497839 (2005).

47. Nakada, M. et al. Suppression of membrane-type 1 matrix metalloproteinase (MMP)-mediated MMP-2 activation and tumor invasion by testican 3 and its splicing variant gene product, N-Tes. Cancer Res. 61, 8896-8902 (2001).

\section{Acknowledgements}

We are grateful to Roman Bonet, Xandra Kreplin and Joan Pous from the joint IBMB/IRB Automated Crystallography Platform and the Protein Purification Service for assistance during purification and SECMALLS experiments. Philippe Leone is thanked for advice and provision of positive control target expression cosntructs to set up the Drosophila melanogaster Schneider embryonic cell system for protein production in the laboratory. This study was supported in part by grants from Spanish and Catalan public and private bodies (grant/ fellowship references BFU2015-64487R, MDM-2014-0435, BES-2015-074583, BES-2016-076877, 2017SGR3 and Fundació "La Marató de TV3" 201815). Yoshifumi Ito from the University of Oxford (UK) and Makoto Noda from Kyoto University (Japan) kindly provided plasmids for the production of human MMP-14 catalytic domain and human RECK, respectively.

\section{Author contributions}

T.G., I.d.D. and F.X.G.R. conceived and supervised the work; S.R.M., L.A.M. and L.M.P. produced and purified proteins, and performed biochemical studies; I.d.D. implemented the S2 overexpression system in the laboratory; and F.X.G.R. wrote the paper with contributions from all authors.

\section{Competing interests}

The authors declare no competing interests.

\section{Additional information}

Supplementary information is available for this paper at https://doi.org/10.1038/s41598-020-63338-4.

Correspondence and requests for materials should be addressed to F.X.G.-R.

Reprints and permissions information is available at www.nature.com/reprints.

Publisher's note Springer Nature remains neutral with regard to jurisdictional claims in published maps and institutional affiliations.

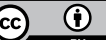

Open Access This article is licensed under a Creative Commons Attribution 4.0 International License, which permits use, sharing, adaptation, distribution and reproduction in any medium or format, as long as you give appropriate credit to the original author(s) and the source, provide a link to the Creative Commons license, and indicate if changes were made. The images or other third party material in this article are included in the article's Creative Commons license, unless indicated otherwise in a credit line to the material. If material is not included in the article's Creative Commons license and your intended use is not permitted by statutory regulation or exceeds the permitted use, you will need to obtain permission directly from the copyright holder. To view a copy of this license, visit http://creativecommons.org/licenses/by/4.0/.

(C) The Author(s) 2020 